\title{
Argentina y negritud: desde la otredad radicalizada hacia discursos más igualitarios
}

\author{
Argentina and Negritude: From Radical Otherness \\ Toward a More Equalitarian Discourse \\ Argentina e negritude: desde a outredade radicalizada \\ para discursos mais igualitários
}

\section{Alejandro Solomianski}

CALIFORNIA STATE UNIVERSITY, LOS ANGELES, ESTADOS UNIDOS

Profesor en California State University, Los Angeles. PhD University of Pittsburgh. Es autor de "Rupturas fronterizas en California y radicalización de la otredad en las representaciones hegemónicas", Babel (University of Toulon, France, 2013), Otras voces. Nuevas Identidades en la frontera sur de California (Dirección general y ensayo crítico, $A$ Contracorriente- North Carolina State University, 2011), Identidades Secretas: La negritud Argentina (Beatriz Viterbo, 2003), "Torture and Nation: A Diachronic Map of Argentine violence" (Hispanic Issues On Line 4.1, 2009). Correo electrónico: asolomi@exchange.calstatela.edu

\footnotetext{
Artículo de reflexión

Algunos datos y fragmentos del presente artículo consideran y reelaboran formulaciones previas de algunas ideas que han aparecido en mi libro Identidades secretas: Muy especialmente en lo referido al nombre de la Argentina. Agradezco a Beatriz Viterbo Editora por autorizar su edición en este nuevo contexto. Documento accesible en línea desde la siguiente dirección: http://revistas.javeriana.edu.co doi: 10.11144/Javeriana.cl19-38. ando
} 


\section{Resumen}

La primera sección de este artículo recupera y analiza tanto el clima académico como la estructura de sentimientos emergentes en la última década del siglo XX que contribuyeron a la expansión de los estudios sobre la afroargentinidad hasta el momento presente. En la segunda parte apunto a la lógica negadora, fundamental para el principio constructivo del imaginario de la identidad nacional argentina y ejemplifico su aplicación en el mismo nombre del país. Destaco el valor de los capitales simbólicos perdidos con una de las primeras grandes figuras históricas de la tradición borrada (Joaquín Lenzina) y con una de las últimas (Gabino Ezeiza).

Palabras clave: afroargentinidad; identidad nacional; configuración de imaginarios; Argentina; procesos históricos; América Latina

\section{Abstract}

The first section of the present article analyses and recuperates both the academic atmosphere as well as the emergent structure of feelings of the last decade of the 20 century that made possible and helped the expansion of the studies of Afro-Argentinity until today. The second section analyses the denying logic, essential to the constructive principle of the imaginary of Argentine national identity. I judge the name of the country as an interesting point to examine. Among the lost Afro symbolic capitals I consider the two more relevant historical "payadores". The first one Joaquín Lenzina, and the last one Gabino Ezeiza, both recuperated here mostly as Argentine intellectuals.

Keywords: Afro-Argentinity; national identity; construction of imaginaries; Argentina; historical processes; Latin America

\section{Resumo}

A primeira seção deste artigo recupera e analisa tanto o clima académico quanto a estrutura de sentimentos emergentes na última década do século XX que contribuíram para a expansão dos estudos sobre a afroargentinidade até o momento presente. Na segunda parte aponto para a lógica negadora, fundamental para o principio construtivo do imaginário da identidade nacional argentina e exemplifico sua aplicação no próprio nome do país. Remarco o valor dos capitais simbólicos perdidos com uma das primeiras grandes figuras históricas da tradição apagada (Joaquín Lenzina) e com uma das últimas (Gabino Ezeiza).

\section{Palavras-chave:} afroargentinidade; identidade nacional; configuração de imaginários; Argentina; processos históricos; América Latina.

RECIBIDO: 5 DE JUNIO DE 2014. ACEPTADO: 19 DE JUNIO DE 2014. DISPONIBLE EN LÍNEA: 01 DE JULIO DE 2015

\section{Cómo citar este artículo:}

Solomianski, Alejandro. "Argentina y negritud: desde la otredad radicalizada hacia discursos más igualitarios". Cuadernos de Literatura 19.38 (2015):

99-118. http://dx.doi.org/10.11144/Javeriana.cl19-38.ando 


$\begin{array}{ll}4019 \quad & \text { Yo sé del fondo del mar } \\ & \text { Donde los pejes nacieron. } \\ & \text { Yo sé por qué crece el árbol, } \\ & \text { Y por qué silban los vientos } \\ & \text { Cosas que inoran los blancos } \\ 4024 \quad \text { Las sabe este pobre negro. } \\ 4037 \quad \text { De lo que un cantor esplica } \\ \text { No falta qué aprovechar } \\ \text { Y se le debe escuchar } \\ \text { Aunque sea negro el que cante. } \\ \text { Apriende el que es inorante, } \\ \text { Y el que es sabio, apriende más. } \\ \text { Bajo la frente más negra } \\ \text { Hay pensamiento y hay vida. } \\ \text { La gente escuche tranquila } \\ \text { No me haga ningún reproche. } \\ \text { También es negra la noche } \\ \text { Y tiene estrellas que brillan. }\end{array}$

JOSÉ HERNÁNDEZ

\section{La conflictiva y conflictuada mirada académica}

Tal vez a un investigador dueño de los criterios "químicamente puros", de las certezas académico discursivas, pudiera parecerle poco "raciológico" encabezar un artículo sobre el estudio de los aportes afroargentinos (al repertorio imaginario de la identidad nacional) con un texto no escrito por un afroargentino ${ }^{1}$. Tengo una serie de excusas. La primera, el texto forma parte tanto de la herencia simbólica afroargentina como de la euroargentina y si nos pusiéramos a "hilar fino", probablemente mucho más de la primera que de la segunda; en consecuencia, es

$1 \quad$ Raza es un significante vacío que adquiere el significado más conveniente para el entramado de intereses, tanto simbólicos como materiales de alternativos grupos hegemónicos. Los matices significativos del significante son dinámicos y no deben interpretarse de un modo unívoco e inflexible. Dentro de los procesos de desarrollo socio-histórico, contribuyen a la configuración de los diversos "contratos raciales". Al igual que la errónea noción de descubrimiento (tan emparentada con la acuñación "moderna" de la percepción racial), las razas, lamentablemente, siguen siendo "realidades biológicas" y tangibles de un modo excesivo. Mis comentarios acerca de Fierro y el Moreno buscan desestabilizar esta noción desde un comienzo a partir de un texto en el que la noción de raza se resquebraja. 
un poema en el que la mayoría de los argentinos pudiéramos sentir nuestro pasado representado. La segunda, el Negro y sobre todo en este segmento, se revela como el mejor payador de este libro tan memorable. La tercera, es que antes de la condensación xenofóbico-racista contra la inmigración italiana y de otras regiones de Europa y del mundo, Fierro se asemeja a lo que contemporáneamente, algunos denominan en Argentina "un negro de mierda": alguien que por el color de su piel, entre otros factores, se asocia despectivamente a la negritud. En su momento, el Negro y Fierro se encontraban, en la escala social, infinitamente más próximos entre sí que lo que pudieran estarlo ambos de un "pueblero" con algunos antepasados guaraníes. Por último, si todos estos motivos no alcanzaran a convencer a quien demandare tal clase de purismo académico, Jorge Luis Borges y Margarita Guerrero (1953), en un texto recorrido por reflexiones agudísimas, proponen que esta payada es el único momento realista del Martín Fierro, en el sentido de que es el único fragmento en el que el poema recoge fielmente la referencialidad concreta de su época, tanto situacional como discursivamente. Por otra parte en "El fin", Borges propone una identificación concluyente entre Fierro y el Moreno (Borges y Guerrero 1953; Solomianski 174)².

No considero necesario entrar en análisis históricos o bibliográficos sobre las relaciones entre el Campo de poder y campo intelectual (Bourdieu 9-36) en el pasado. Aunque tal vez sea apropiado marcar puntualmente las tensiones que continúan intensificándose hacia el interior del "campo intelectual". Un espacio que necesariamente, por su lógica propia, es de naturaleza competitiva y jerárqui$\mathrm{ca}^{3}$, ha estado enfrentando nuevas fuentes de conflicto en las últimas décadas. Las nuevas tecnologías de la escritura, el archivo de la información y la comunicación de las más diversas especificidades textuales, resultan maravillosas a la hora de construir objetos del conocimiento, sin embargo, el fundamento lógico de estas tecnologías apunta hacia la rapidez, la superficialidad y la brevedad. El "hábito" de lectura se exalta en función de la velocidad de conexión, cada vez mayor, con la web.

Evidentemente el trabajo del "campo intelectual", por lógica propia, necesita otra relación con el fluir temporal y la profundidad de sus objetos de elaboración. Más allá de su ambigua relación con las nuevas configuraciones de los fluidos

2 Habla muy mal del sistema educativo argentino, respecto a esta temática concreta y a su construcción de realidad presupuesta, el hecho de que alguien formado en escuelas de excelente nivel (como la Universidad de Buenos Aires) y con maestros excepcionales, se haya enterado del valor literario de los textos (e incluso de su mera existencia) de Horacio Mendizábal o Gabino Ezeiza, a partir de dos libros estadounidenses en inglés.

3 A veces algunos miembros parecieran creer que es, en rigor, una colectividad monárquica. 
comunicativos, la actividad intelectual debe enfrentar las reestructuraciones de los espacios de poder social y sus lógicas de fundamentación, tanto simbólicas como materiales. Posiblemente, la instrumentación de recortes presupuestarios en todos los niveles educativos en la mayoría de las naciones, la pérdida o disminución del poder político de las voces sólidamente intelectuales, y en definitiva, la subordinación de lo intelectual a la sintaxis irracional del dinero, amenaza al espacio académico con la creciente disminución de sus miembros y el deterioro salarial y de las condiciones laborales en general. Estos múltiples "collares de ahorque" impulsarían los esfuerzos del trabajo académico hacia una lógica prostituyente, según la cual, el hallazgo de temáticas, metafóricamente, sexies sería lo prioritario a la hora de escoger un proyecto de investigación. Sin embargo, sorprendentemente, en líneas generales, el efecto más frecuente ha sido una apertura hacia temáticas innovadoras en las cuales la honestidad política e intelectual parece haber sido la respuesta frente a los mencionados contextos amenazadores.

Para aquellos que se dedican a establecer los mapas dispersos y heterogéneos de las diversas y numerosas tradiciones afrolatinoamericanas, borradas, distorsionadas y negadas muy frecuentemente, los últimos quince años (al menos) representan una creciente emergencia, reconfiguración y desarrollo de las disciplinas y los materiales fundacionales de este campo de estudios. Tal vez puede considerarse obvio que la afrolatinoamericanidad, además de un constructo epistemológico realizado a partir de textos, testimonios e imágenes, es un repertorio inmensamente extenso de vivencias existenciales, de materialidades, voces y estructuras de sentimientos concretas. Coherentemente, las comunidades epistemológicas que han negado fragmentos imborrables de sus pasados históricos y de sus identidades presentes, tienden a persistir en la negación o desvalorización de los grupos humanos que encarnan numerosas y disímiles identidades afrodescendientes.

Puede señalarse con alegría y entusiasmo que en los últimos quince años los estudios sobre esta temática se han extendido y desarrollado postulando nuevos modos de entender los procesos constitutivos de la Modernidad y de Occidente, empezado a entrelazar itinerarios cognitivos previamente imprevisibles. Pero no debiera perderse de vista que este despliegue dentro del campo académico tiene que percibirse contextualizado y en relación con diversos factores y al menos en el caso argentino, debe remarcarse la confluencia de una actividad contundente, inteligente y perseverante por parte de las colectividades afrodescendientes y la considerable efectividad de su activismo social.

En mi caso personal no puedo dejar de mencionar a algunos de los activistas con los que tuve la suerte de trabajar y sin cuya ayuda hubiera obtenido 
resultados menos intensos, o tal vez no hubiera obtenido ninguno. La lúcida e infatigable Miriam Gomes, profesora de historia y perteneciente al grupo afrodescendiente caboverdeano, ha sido y sigue siendo una gran interlocutora y mentora para todo proyecto intelectual que contribuya a restablecer la realidad socio-histórica argentina. Miriam Gomes, entre otras numerosas actividades, ha participado en los primeros censos de reconocimiento de los afrodescendientes, ha colaborado en documentales, ha organizado presentaciones de libros y establecido numerosas conferencias. Pocha Lamadrid, con su pionera agrupación África Vive, ha ayudado a la difusión de la problemática y resaltado a nivel nacional el punto básico de la visibilidad. Lucía Molina, quien fundó la Casa de la Cultura indoafrolatinoamericana en Santa Fe, es una comunicadora brillante e incansable que ha colaborado al desarrollo de este nuevo clima de apertura perceptiva dentro de la esfera pública argentina. Organizaciones como IARPIDI (El instituto Argentino para la Igualdad, Diversidad e Integración) o el DIAFAR (Movimiento de la Diáspora africana en la Argentina) han tenido como condiciones de posibilidad para su existencia, conjuntamente con otros numerosos factores, el trabajo de las activistas previamente mencionadas (no casualmente mujeres), la labor determinante de las diversas agrupaciones de lucha por los derechos humanos y la inteligente utilización por parte del campo activista de algunos de los aportes de los equipos intelectuales que han trabajado y lo siguen haciendo, sobre el tema. Es destacable la efervescencia de estas agrupaciones y su clara conciencia de lucha contra toda forma de discriminación, racismo y ultrajes a los derechos humanos.

Siguiendo esta línea del activismo, resulta asombroso constatar los logros del sector del campo intelectual argentino ocupado en esta problemática, como por ejemplo, Las poblaciones afrodescendientes de América Latina y el Caribe. Pasado, presente y perspectivas desde el siglo XXI (Becerra, Buffa y Noufouri, Ayala, 2012). Este volumen colectivo, impensable hace diez años, logra abrir el mapa cognitivo sobre una multiplicidad de temas, ampliando con profundidad científica la temática, originalmente denostada, de la afrolatinoamericanidad. En líneas generales, entre otros esfuerzos institucionales, resultan destacables los remarcables aportes de la Universidad de Tres de Febrero y su Comisión permanente de Estudios Afroargentinos. Comparativamente, el espacio que la Universidad de Buenos Aires ha dado a esta problemática resulta aún hoy, significativamente menor.

En este sentido, me parece justo destacar que mis primeros acercamientos a la problemática los realicé a través de dos libros estadounidenses: The AfroArgentines of Buenos Aires (Andrews, 1980) y Afro-Argentine Discourse: Another 
dimension of the Black Diaspora (Lewis, 1996). En ambos casos se trata de estudios originales, profundos y creativos ${ }^{4}$. También debiera destacarse que ambos investigadores han continuado con una producción que se dedicó a aumentar la información sobre la temática en otras áreas de Latinoamérica. En mi opinión, son dos libros fundacionales dentro de este campo, y personalmente me han resultado indispensables para realizar mi investigación e incluso yo diría que son una fuente de inspiración permanente para muchos de los que han trabajado esta temática. En mi caso personal, no he podido dejar de considerarlos en una tesis de doctorado, en el libro que la corrige (al cual añadí cuatro nuevos capítulos) y en seis artículos de números especiales de revistas académicas o en capítulos de libros donde, con mayor distancia, reexamino la producción concreta de intelectuales afroargentinos. De todos modos, encuentro apropiado señalar que, más allá de la admiración que los mencionados libros me producen, me parece intelectualmente fructífero el cuestionamiento de algunos aspectos generales en los que se sostienen.

El entendimiento del significado del Rosismo (1829-1852) en la configuración de la argentinidad, resulta, cuando no esquemático, desdibujado o implementado tomando como presupuesto la constelación de narrativas inflexiblemente antirrosistas que circulan con mayor apariencia de certezas en la academia estadounidense que en la argentina. Punto de extremada relevancia, ya que los afroargentinos fueron la base poblacional cuyo apoyo consolidó el arribo al poder de Juan Manuel de Rosas y colaboró con su extenso mantenimiento. Aunque a mi entender, de un modo ni lejanamente parecido al que José Mármol propone en Amalia (1995), o en su lamentable e involuntariamente humorístico panfleto Manuela Rosas. Rasgos biográficos (1917). El problema resulta más complicado en el libro de Andrews, que es específicamente, un libro de historia. Me atrevería a proponer que cuando uno explora y amplifica (borrando o ignorando matices contextuales significativamente explicativos) el racismo de países otros, que en varios aspectos se distancian del país al que uno pertenece y de cuyo racismo el texto propio se aparta, aunque sea involuntaria o inconscientemente,

4 Evidentemente son dos libros en los que no se trata una problemática muy (o tal vez nada) sexy para la órbita de intereses de la academia latinoamericanista estadounidense. Siguiendo la lógica jerárquica del campo intelectual, sus autores han sido profesores en muy buenas universidades (gracias al mérito de sus trabajos), pero no en aquellas que se consideran centrales. No es una mera coincidencia. Simplificando la cuestión al extremo podría pensarse en la tendencia a la marginalidad de las esferas de investigación renovadoras del presente y la tendencia a la consagración de las temáticas reproduccionistas del pasado. Aunque, evidentemente, no puede hacerse de esto una regla. 
la operativa simbólica tiende a mitigar el racismo del país de pertenencia. Creo que el racismo estadounidense en muchas ocasiones es una herramienta fértil para establecer diversas formas de racismo y sus lógicas de funcionamiento. De ninguna manera pongo en duda la "salud" ideológica del libro de Andrews ni cuestiono sus inobjetables buenas intenciones. Solo intento descifrar el origen de una lectura a veces muy rígida en mi opinión, de algunos procesos históricos.

El caso de Lewis es diferente. Ante todo es un libro que documenta una variada y relevante cantidad de textos afroargentinos; en el caso de algunos pocos fragmentos, extremadamente significativos, transcribe solo su propia versión en inglés, apartando del lector latinoamericano textos originales que hubieran acrecentado el valor de una recolección maravillosa e inspiradora (supongo que el hecho nos dice algo acerca de la audiencia implícita). Dejo de lado los criterios clasificatorios de los textos estudiados que son en mi opinión, debatibles y el hecho de que la monografía (coherentemente) no reflexiona sobre este tipo de cuestiones contextuales. Disiento con el libro de Lewis (y este es un hecho inevitable consecuencia de las ubicaciones diversas de los sujetos de la enunciación) en un principio más determinante que su visión del rosismo y la cultura popular. Disiento en la concepción de la lógica que está en la base para la formulación y comprensión de estos textos: mi lectura apunta a la determinación del corpus textual afroargentino y su marco de pertenencia general. Marvin Lewis considera que todo enunciado producido por un afroargentino debe ser entendido, analizado y explicado a partir de su pertenencia al contexto de la diáspora africana, en tanto fragmento o capítulo de ella y del desarrollo de sus procesos históricos, dejando de lado el espacio, la historia y las redes discursivas contextuales dentro de las cuales y en relación con las cuales dichos textos fueron producidos. $\mathrm{Mi}$ propuesta, en función de este factor de la pertenencia, podría considerarse como el desarrollo de la tesis opuesta.

En mis estudios, he observado que cuando un intelectual afroargentino hace referencia a la diáspora africana, esta resulta un tema que aparece tratado con mucha menor frecuencia que la que uno habría anticipado, en tanto que el reclamo por los derechos a la igualdad y el reconocimiento que la argentinidad y la participación de los ancestros en las guerras de la Independencia otorgan es una discusión profusa y más inmediatamente justiciera. Entiendo que la diáspora tiende a aparecer como un tema que el escritor afroargentino utiliza para operar simbólicamente en sus contextos más inmediatos. De este modo a mi entender, la forma más productiva y coherente de comprender esta inmensa variedad de textos, que exceden lo que histórica y geográficamente llamamos Argentina para entremezclarse en ámbitos como el Virreinato del Río de la Plata, la Liga artiguista 
de los Pueblos Libres o las Provincias Unidas del Sud, consiste justamente en re-contextualizar esta producción textual con sus conflictivos espacios de enunciación. Este reposicionamiento en sus esferas de origen permite vincularla con la lucha por los intereses de la comunidad representada, pero también nos permite percibir la competición por la legitimidad intelectual tanto en el ámbito argentino en general (el espacio conflictivo que reúne lo afro y lo euro) como dentro mismo del campo específicamente afroargentino, en este caso especialmente en términos de la auténtica representatividad. Supongo que resulta asaz transparente que la interpretación de Marvin Lewis se vincula con su agenda intelectual y política que, enfocada hacia un público estadounidense, reivindica la proliferación de intelectuales pertenecientes a la alta cultura letrada a lo largo y a lo ancho de la diáspora. Entretanto mi intento siempre ha sido entender y revivir aquellas partes de nuestra identidad nacional secretas (ocultas) mediante el "genocidio discursivo" institucionalizado por ideólogos como Bartolomé Mitre (1961) o Sarmiento (1971).

Entre 1991 y 1993 los paradigmas referentes a la nociones de centro, periferia, civilización, imperialismo, "descubrimiento", y otros componentes de la misma constelación semántica eurocéntrica, comenzaron a destartalarse en tanto certezas de los viejos sectores hegemónicos. El Quinto Centenario (1992), más allá de los espacios académicos, puso en juego una notable alteración de los papeles entre el occidente europeizante y la América originaria. Un remarcable repertorio de compensaciones simbólicas se puso en práctica y entre muchas otras cosas festejables, Rigoberta Menchú obtuvo un más que merecido Premio Nobel de la $\mathrm{Paz}^{5}$. La agitación de las organizaciones aborígenes y sus simpatizantes encontraron, en líneas generales, por parte de los equipos culturales de los organismos de gobierno latinoamericanos, una repercusión que se tradujo en una significativa producción de bibliografía altamente relevante. Por su parte España, a través de la Sociedad Estatal Quinto Centenario, contribuyó con una cuantiosa significativa producción intelectual y apoyó un cambio de perspectivas, al menos en el plano simbólico.

Si bien la academia estadounidense empezó a ceder espacios a proyectos como el de Beverley (1993), Gilroy (1993) que evidentemente excede el campo latinoamericanista, Mignolo (1995) y en menor medida Dussel (1992), simultáneamente entronizó dos libros que en mi opinión, apuntan en la dirección opuesta a los

5 Entiendo que en este contexto es innecesario enfatizar que el premio no le fue otorgado por el libro en el que, para ponerlo en los términos administrativos aceptados, Elizabeth Burgos recoge su testimonio. La tremenda difusión, incluso mucho más allá de la academia, del difícilmente sostenible libro de David Stoll (1999) reafirma lo mencionado acerca del atractivo previo de las isobaras de prestigio que recorren el campo intelectual o del menguado interés de diversos proyectos en relación con el campo del poder. 
proyectos mencionados, como si pudieran funcionar a la manera de un contrapeso neoliberal frente a un mundo que parecía persistir en intentar transformarse. Estos textos han funcionado a la manera de un horizonte de comprensión, seguramente el más limitador e indiscutible para los Estudios Culturales latinoamericanistas por cerca de una década, posiblemente, más allá de los méritos y las intenciones de sus autores. En definitiva, considero que esta entronización, prácticamente absoluta, fue ante todo el producto de las necesidades de una época y de su entrecruzamiento con los lectores del campo intelectual estadounidense. En el caso de las culturas populares y la modernidad, el libro de García Canclini (1990) terminó siendo una entusiasmada y entusiasmante celebración del proyecto Tijuana y los beneficios del libre mercado. En el caso de la recuperación del canon y la alta cultura, el libro de Doris Sommer (1991) vino a imponer una lectura de la configuración de los estados nacionales latinoamericanos que privilegiaba la "unión amorosa" por encima de historias, territorios y conflictos desgarradores, dejando de lado el héterosexismo agobiante y la exaltación acrítica de los valores burgueses del siglo XIX. Descartando incluso el problema de la excesiva manipulación de los datos en función de conclusiones establecidas de antemano.

La mayor complicación que encuentro en el libro es su elaboración del concepto de raza. Sería terriblemente extenso discutir los detalles al respecto pero el ejemplo obvio del capítulo "Sab C' moi" y su referencia a la alta cultura francesa remiten a una posición que se auto-legitima en el entramado de alusiones literarias y en una lectura acrítica en términos del positivismo racista y aristocrático que limita a Gómez de Avellaneda. El capítulo dedicado a Amalia, además de proponer un libro inaceptable como ficción fundacional de la argentinidad, ejercita una lectura apasionada y entusiasta de un texto extremadamente parcial en su posición ideológica y estéticamente muy pobre. Podría pensarse que su antirrocismo y su racismo son tan exagerados que por momentos no solo resulta obsoleto sino, en alguna medida, humorístico. Esta interpretación que posiblemente solo podía establecerse a partir y en función de un contexto estadounidense, instaura una configuración de la argentinidad basada en los aportes y el dominio de la burguesía blanca porteña y la colaboración de un interior terrateniente, blanco y feminizado. Todavía en 2008, cuando muchos y relevantes textos producidos por afroargentinos ya se encontraban difundidos en varios libros y revistas académicas, he llegado a ver un libro que, intentando discurrir sobre la identidad argentina, ignora o rechaza ostensiblemente los aportes imprescindibles de la afroargentinidad (Kaminsky).

Como puede observarse, el campo académico estadounidense enfrenta la afrolatinoamericanidad de un modo doblemente complejo: por un lado el entramado de compromisos con el mercado-campo intelectual local, por el otro 
el cuestionamiento de las perspectivas según la combinatoria de identidades originarias que configuran al sujeto intelectual. A riesgo de no mencionar otros estudios recientes meritorios ${ }^{6}$, quisiera cerrar esta sección nombrando al menos un par de volúmenes tan novedosos como genuinos. Entiendo que gracias a su mirada más distante y plural de la conflictividad, la variedad y la amplitud siguen fortaleciendo la productividad del campo cultural estadounidense. En 2011 Patricia Valldarez-Ruiz editó una "Special Issue on Afro-Hispanic Subjetivities" para la Cincinnati Romance Review. Su esmerada colección de artículos demuestra la vigencia y creciente vitalidad del campo en este contexto. Por último el volumen Pensar el siglo XIX desde el siglo XXI, editado y compilado por Ana Peluffo (2012), aunque no trabaja con la afrolatinoamericanidad específicamente, establece un ejemplo de aproximaciones diversificadas al estudio del siglo XIX en Latinoamérica a partir de las cuales pueden percibirse lecturas renovadoras cuya perspectiva se aparta notablemente de las jerarquizaciones neoliberales.

\section{La identidad secreta de la negritud dentro del imaginario nacional argentino}

En este apartado, una vez realizado el intento de demarcar de manera general el contexto situacional de los enfoques académicos al respecto, intentaré sintetizar mi entendimiento del proceso histórico ideológico de invisibilización de la afroargentinidad. Básicamente mi concepción no ha variado de la que expreso y argumento extensamente en mi libro del 2003. Me emociona ver las transformaciones sociales de la Argentina y el renovado enfoque de la temática más allá del campo académico. Pero mi investigación original apuntaba a la configuración del imaginario hegemónico de la identidad nacional argentina, dentro del cual se había distorsionado (Mitre y su invención del personaje "Falucho")7 y negado la mera existencia (Sarmiento y su genocidio discursivo) de los afroargentinos cuando todavía eran una presencia extremadamente visible (posiblemente agobiante para las capas blancas) en el panorama poblacional argentino. En este apartado analizaré parte de los aspectos ideológicos e históricos que condujeron a esta situación y que la demuestran. Intentaré ser conciso.

En un giro copernicano de extraordinaria profundidad y paradójica sencillez, René Depestre señala que "En la caza etnocentrista de africanismos, antropólogos y etnólogos han mantenido la herencia europea fuera del alcance de sus inventarios. [...] No existe una etnología de las 'capas blancas' de nuestras

$6 \quad$ Es un problema en alguna medida inevitable con los textos muy recientes.

7 Cualquier similitud con la referencia a un pene de baja categoría o a errar podría no ser mera coincidencia. 
poblaciones" (339). Reconfigurando la lúcida observación de Depestre, puede postularse que, ya desde la misma institución de las disciplinas académicas (sujetos) y sus objetos de estudio, se establece una lógica jerárquica, autoritaria y eficazmente productora de otredad como horizonte limitador a la consciencia de la pluralidad y la visión de lo "diferente". Esta distorsión eurocéntrica y sistemática invade, independientemente del racismo batallante y consciente de algunos sujetos y muy especialmente en Argentina, la estructuración lógica de sus organismos oficiales. Tras el derrocamiento de Rosas esta mirada que se nutre de la percepción europeísta, logra establecer como universalidad lo que es meramente una mirada parcial configurada autoritariamente, $\mathrm{y}$ algunas veces por el poder persuasivo del glamour del prestigio, desde algunos espacios de Buenos Aires (punto de empalme con el mercado europeo). En consecuencia, el repertorio hegemónico de imágenes de la argentinidad, sus archivos históricos, su aparato educativo y la composición de su canon literario se formulan dentro de la ficción de la blanquedad absoluta y la negación y el rechazo de los aportes esenciales de la negritud.

Aún hoy, y con todas las transformaciones que empiezan a visualizarse, para la mayor parte de los argentinos, la mera mención de la noción negritud argentina carece de referencia. Puede pensarse como una broma racista que se refiere a los pueblos originarios o como una emisión excéntrica y carente de sentido. La referencia a los negros, con la implicancia de africanidad y del pasado por la experiencia de la esclavitud, carece de sujetos visibles. Aquellos que se ven en la patria son percibidos como extranjeros, principalmente uruguayos o brasileños o como africanos (más allá de que hayan obtenido la nacionalidad o no) pertenecientes a las migraciones de finales del siglo XX. Esta persistente invisibilidad se extiende para todo el siglo XX y está determinada a partir de variantes históricoideológicas, para todo el pasado argentino (o nacional, que no son sinónimos exactos) ${ }^{8}$. Aún aceptando su existencia pasada, la presuposición más extendida y común (e incluso ingenua podría decirse) sugiere que si en el pasado hubo tal población, esta debe haber sido reducida en número y sus aportes culturales escasos o irrelevantes; caso contrario deberían haber dejado algún vestigio, algún tipo de signo imborrable y contrastante que señalara la peculiaridad africana en el país más europeo de América Latina.

8 El tema de la configuración de la nacionalidad en permanente ebullición y transformación, por un lado, y la determinación de su nombre, en tanto operativa simbólica estabilizadora de enorme relevancia y significado, será comentado en estas páginas dentro de las restricciones lógicas de espacio. 
Más allá del racismo involuntario e ingenuo que la percepción propia del pseudo-sentido común manifiesta, resulta oportuno destacar la torpeza con que aplica, atribuye y distribuye la noción identidades, transformando entidades cambiantes, complejas, contradictorias y determinadas por el entorno contextual en un mero atributo simple, inmodificable y absoluto. En principio los afroargentinos esclavizados durante la colonia (e incluso después de los avances de la Asamblea Nacional de 1813) se parecen mucho a otros habitantes de la región con los cuales convivieron dentro del entramado de la hermandad difícilmente segmentable del proletariado rioplatense. Tal vez sea conveniente especificar que el antiesencialismo desde el que formulo estas reflexiones de ninguna manera desecha "posmodernistamente" los enfrentamientos y configuraciones de identidades a través de y en conjunto con los procesos históricos. Es verdad que Bernardino Rivadavia, alias el "Doctor Chocolate", una de las figuras más europeizantes de nuestra historia y oficialmente registrado como nuestro primer presidente, tuvo ancestros africanos. Este detalle (considerablemente racista si se analiza el conjunto de referencias al hecho en su totalidad ) no cambia el desarrollo histórico de la Argentina en el que permanentemente hubo un grupo opresor (clasificable como "euroargentino") identificado con un concreto sistema ideológico cultural (eurocentrismo capitalista) y diversos grupos oprimidos ${ }^{9}$. De estos grupos, de acuerdo a los censos registrados y en alguna medida manipulados (Andrews 90-92) al menos hasta las primeras décadas del siglo XIX, el más extenso estaba integrado por afroargentinos; sobre todo si recordamos que las poblaciones originarias estaban en el "desierto", es decir fuera del territorio, del mapa y de la humanidad. En rigor en esta relación de explotación donde ambos grupos resultan implicados (basta leer "El matadero" de Esteban Echeverría para visualizar hasta qué punto una parte configura la otra), la historia de la negritud argentina es también, necesariamente, la historia de la blanquedad, aunque esta última, para numerosos sujetos, no pueda ser vista como un aspecto fragmentario y se les auto-represente "evidentemente" y automáticamente como el único desplegarse de la argentinidad. En líneas generales, la percepción de la blanquedad como única forma posible de argentinidad, traspasa las fronteras de clase social ${ }^{10}$, afiliación política y nivel

9 Realizar no un análisis sino un mero recuento del despliegue zigzagueante, complejo y múltiple de la historia de la entidad que hoy llamamos Argentina es pragmáticamente imposible y excede geométricamente los límites de este artículo. Intercalaré algunos núcleos analíticonarrativos mínimos relativos a la afroargentinidad.

10 Siguiendo la propuesta de Charles Mills (1999) el contrato racial articula la organización de las sociedades occidentales y establece al racismo como uno de los componentes inherentes de la subjetividad. 
cultural general. Esta forma de "ceguera" no se origina necesariamente en una predisposición racista y penetra incluso el aparato perceptivo de sujetos desprejuiciados y en principio, abiertos a las diferencias étnico-culturales ${ }^{11}$.

La base de mi propuesta es invertir este telón de fondo preestablecido como tan claramente lo expresara Depestre. No se trata de demostrar y reivindicar las contribuciones de raíces africanas en la configuración de lo popular argentino, o de destacar los remarcables aportes de individuos afroargentinos a la "alta cultura" del país, sino de analizar la manera en que estos materiales son obturados o reconfigurados distorsionadamente en la construcción del imaginario nacional argentino. Sería una especie de etnología invertida en la que para poner en cuestión los presupuestos más obvios del discurso hegemónico y revelar sus mecanismos operativos, se hace necesario asumir la perspectiva subalternizada.

Para empezar, el mero hecho de que hoy podamos hablar de la Argentina en el dialecto rioplatense no deja de vincularse con la más que considerable participación de afrorargentinos en la defensa de Buenos Aires durante las Invasiones Inglesas de 1806 y 1807, cuya cantidad y participación, ya sea en las milicias oficiales como en la resistencia civil, resultaron decisivas para las consecuencias históricas definitivas. Del mismo modo, el rol activísimo de los regimientos de "pardos" y "morenos" durante cerca de una década y media en la Guerra de la Independencia (conjunto de batallas extremadamente complejo como para definirlo a través de esa simplificación de manual escolar) fue la condición de posibilidad para el experimento histórico posterior de las nacionalidades hispanoamericanas. En este contexto, su apoyo entusiasta al gobierno de Juan Manuel de Rosas fue necesario para la configuración del país. Justamente los únicos logros indiscutibles de esta figura histórica (o al menos más ampliamente aceptados) fueron precisamente, la defensa de la independencia nacional frente a las pretensiones de las potencias europeas y la efectiva y duradera consolidación de una unidad y autoridad nacionales. Lamentablemente, la ofrenda de la propia corporalidad en los combates para constituir la nacionalidad es la contribución más fácil de desvanecer, la más encubrible y olvidable, sobre todo si los propietarios del capital simbólico y aquellos especializados en labrar las narraciones de los acontecimientos históricos están mucho más dispuestos a borrar o a distorsionar que a homenajear a quienes lo merecen. Al fin y al cabo, solo se trata de cadáveres caídos en los campos de batalla, cuerpos efímeros, vestigios de huesos.

11 Considero que el libro de Teun Van Dijk (1987) es sumamente útil para comprender y matizar estas cuestiones. 
En rigor, mucho de lo que hoy es considerado típicamente argentino y, como tal, goza de repercusión internacional se encuentra, en menor o mayor medida, vinculado con prácticas culturales afroargentinas en sus orígenes (mucho más difíciles de borrar que el cuerpo sacrificado en la batalla o la participación de los sectores subalternos en el circuito de producción económica), o en prácticas sincréticas en las que "pardos y morenos" ocuparon espacios de máxima relevancia. Sobre la relación entre el candombe, la milonga y el tango se ha escrito muy extensamente y se trata de una evolución difícilmente discutible. Muchos de los primeros intérpretes, compositores e incluso letristas de tangos fueron negros $^{12}$. El mundo negro, en numerosos sentidos, que tan irónica, despectiva y resentidamente describe Esteban Echeverría en El matadero (1991) se focaliza repetidamente en las achuradoras, mayoritariamente mujeres negras que recolectaban los restos vacunos menos valiosos monetariamente y que hoy coinciden con muchos de los platos de la famosa parrillada argentina.

Muchos de los más grandes payadores fueron negros, y un ejemplo notable es Joaquín Lenzina (Ansina, el payador de Artigas), uno de los primeros de los que se tenga registro histórico. Hijo de esclavos africanos, fue liberado por el prócer y actuó desde un comienzo en la gesta patriótico-libertaria. Su acción marcadamente intelectual (una especie de ministro de cultura y difusión en su contexto) lo convirtió en poeta, ideólogo, representante y promotor de la lucha de la Confederación de los Pueblos Libres. Derrotado Artigas, Lenzina acompañó a su amigo hasta el final en su prolongado exilio en el Paraguay. Puede agregarse que hacia los finales históricos de la consensuada vigencia del género payadoril, el maestro por antonomasia era Gabino Ezeiza. Y sus aportes generales lo vuelven una figura paradigmática para el entendimiento de formulaciones históricamente aceptables del imaginario nacional argentino ${ }^{13}$.

12 Apunto a remarcar irónicamente el aún vigente y difundido prejuicio acerca de la predisposición innata (hereditariamente transmitida) de los negros hacia lo rítmico-musical en detrimento de sus habilidades lógico-discursivas.

13 Para deleitarse con la originalidad y los avatares de la figura histórica de Ansina los siguientes libros son recomendables: Memorias de Ansina (Bracco, 1994), Ansina me llaman y Ansina yo soy (Equipo interdisciplinario de la Memoria de Ansina, 1996) y Artigas en la poesía de América (Hammerly Dupuy-Hamerly Peverini, 1951). El capítulo 4 (75-97) de mi libro Identidades Secretas: la negritud argentina (2003) se ocupa casi exclusivamente de analizar la figura y algunos textos de Ansina. Los libros de Ezeiza $(1897,1910,1916)$ y la recopilación Recuerdos del payador (1946) deberían considerarse una parte consistente y relevante del canon literario argentino. A través de todo mi libro (2003) hago numerosas referencias a la importancia de la figura intelectual de Ezeiza, y lo estudio con cierto detenimiento en el capítulo 7 (181-229). En un artículo del 2011 enfatizo la densidad y pertinencia de su itinerario y su producción en el entramado de discursos configuradores de la identidad nacional. 
Intentaré ejemplificar la incontable diversidad de acciones y mecanismos mediante los cuales se distorsionaron u obturaron los componentes afros del imaginario nacional argentino mediante el análisis de su denominación. En función del proyecto nacional, el nombre del país resulta marcadamente significativo para la configuración de su imaginario: el evidente y esquemático contraste con los nombres de los países limítrofes resulta revelador y a simple vista establece una peculiaridad. De todos ellos, Chile, Uruguay, Paraguay, Brasil y Bolivia, es solamente el último mencionado el único que no se denomina mediante una palabra aborigen. De todos modos, si bien Bolivia no es una palabra originaria y por lo tanto no expresa claramente una distancia negadora de lo europeo y reivindicativa de lo autóctono, su resonancia apunta a una constelación semántica donde el elemento independentista es lo primordial; de este modo, más allá que el modelo europeo pueda llegar a percibirse (presente en su mínima expresión), es una tendencia de alejamiento del eurocentrismo la que aparece finalmente enfatizada. Cabe destacar que muchos de los que hoy son países limítrofes de la Argentina fueron en el pasado parte del Virreinato del Río de la Plata y formaron parte, con diversos matices, del proyecto de las Provincias Unidas del Sud. Pensando en este proceso, Paraguay fue sin dudas la nación que más contrastó con la Buenos Aires centralista en función del eje de la autoctonía, tanto en su mera denominación como en el modelo de Estado que implementó bajo el mando del doctor Gaspar Rodríguez de Francia.

Argentina, palabra que hoy se encuentra inevitablemente ligada a las imágenes de la llanura pampeana y de lo gauchesco, es en su origen un latinismo culterano derivado de la palabra latina argentum. De acuerdo al diccionario Vox Latino-Español dicho vocablo se refería (y lo expongo siguiendo el mismo orden de la fuente) a la sustancia metálica plata, por añadidura a los objetos producidos con este material, por último aludía a la monedas de plata y al dinero en general.

En el Río de la Plata, o al menos en Buenos Aires, plata es la expresión más frecuente y dominante en un registro de lengua intermedio, para significar dinero, específicamente papel moneda y más abstractamente riqueza material. "Dinero", "bienes" y "capital", en general, corresponden a un registro de lengua superior, más restringido y específico. Siguiendo esta línea, la asociación que se vincula inmediatamente con el significante plata es siempre el papel moneda circulante o la riqueza material acumulada, jamás la sustancia material, a menos que se diga "collar de plata" u otra expresión semejante. De un modo no explícito, pero tampoco enteramente velado, la nación y el dinero aparecen vinculados entre sí y tienden a identificarse en el nombre del país. Curiosamente, en coherencia con el procedimiento simbólico de distorsión de los referentes 
en función de su aparición reconvertida dentro del imaginario nacional, en el territorio argentino jamás se explotó sistemáticamente un gramo del metal precioso al que alude su nombre. Como contrapartida la carga significativa de dicho nombre se asocia a las nociones de moneda y expansión capitalista a la vez que expresa, mediante la palabra latina argentum, un homenaje a la "alta cultura" europea concebida como la evolución de la tradición grecolatina. Es de notarse que la persistencia histórica de la palabra argentina se sostuvo mayormente a través de su reiteración en textos literario-poéticos cuya afiliación a la cultura eurocéntrica es obvia ${ }^{14}$.

Un detallado y minucioso recuento sobre el origen de la palabra y sus aplicaciones se encuentra en el libro de Rosenblat El nombre de la Argentina (1964). Este volumen sirve como apoyo a mi enfoque de la cuestión si no se considera la elección del nombre como un acto comunitario consciente (y en alguna medida puntual), sino más bien como el gradual desarrollo de un proceso oscilante y por momentos contradictorio, pero que visto en perspectiva actualiza y confirma las variables de un juego ideológico.

La referencia sensorial y simbólica de la plata metálica (parcialmente ya analizada) implica además, tanto en lenguaje poético como en lenguaje coloquial, la imagen visual de la blancura; se instaura de este modo una afirmación celebratoria de lo "blanco-europeo" y una mitigación, "lavado" y negación del ámbito de la negritud africana y también la de los pueblos originarios ${ }^{15}$. De esta manera, el imaginario de la identidad nacional confirma que Argentina tiende a ser el país más rico, más culto (en otras palabras más europeo) y evidentemente el más blanco de América Latina.

El complejo desarrollo histórico e inmigratorio de la nación posee una multitud de núcleos narrativos que ayudarían a sostener aún más sólidamente la tesis presentada. Pero la prolongación del tratamiento de semejantes materiales resulta totalmente desproporcionada en el texto presente.

La primera sección de este artículo recupera y analiza tanto el clima académico como el clima de época que contribuyeron a la expansión de los estudios sobre la afroargentinidad hasta el momento presente.

En la segunda parte apunto a la lógica negadora, fundamental para el principio constructivo del imaginario de la identidad nacional argentina y ejemplifico

14 El trabajo histórico de compilación de poesía patriótica La lira argentina, finalizado por Ramón Díaz justamente en 1824, confirma la presente dirección del análisis.

15 Piénsese en la conexión entre el exterminio llamado Campaña al Desierto y la fundación de la ciudad de La Plata, capital del estado de Buenos Aires, ambas realizadas en 1880. 
su aplicación en el mismo nombre del país. Destaco el valor de los capitales simbólicos perdidos con una de las primeras grandes figuras históricas de la tradición borrada (Joaquín Lenzina) y con una de las últimas (Gabino Ezeiza).

Quizás podría intentar agregarse un nuevo apartado: "las voces recuperadas". Sin embargo, dentro de la extensa, compleja y multifacética producción afroargentina (que, en mi opinión debe ser percibida ante todo como argentina) sería inapropiado, carente de contexto e incluso ocultador, decidir entre Ansina, Mendizábal, Noguera, Elejalde, Luis García Morel, Gabino Ezeiza, Dionisio García, Jorge Miguel Ford o Casildo Thompson, para mencionar a las figuras recuperadas, pertenecientes al siglo XIX o en gran parte anteriores al siglo XX.

A diferencia de cuando emprendí esta investigación quince años atrás, hoy las voces borradas que retumbaban por su ausencia resultan crecientemente accesibles mediante nuevos estudios que las analizan del modo merecido y las recontextualizan. Mucho material ha sido puesto disponible en la web y hay numerosas reseñas y estudios de los estudios que brindan un panorama más profundo y abarcador sobre esta pluralidad discursiva.

Creo que esta diversidad de voces sólidas y estentóreas tiene, aún hoy, mucho que decirnos acerca de quiénes somos y qué somos los argentinos. Mediante su lectura tal vez podamos ver que el país no es, en más de un sentido, el que estábamos acostumbrados (forzados quizás) a percibir.

\section{Obras citadas}

Andrews, George Reid. The Afro-Argentines of Buenos Aires. Madison: The University of Wisconsin Press, 1980.

Barcia, Pedro. Ed. La lira argentina o colección de las piezas poéticas dadas a la luz en Buenos Aires durante la guerra de su independencia. Buenos Aires: Academia Argentina de Letras, 1982.

Becerra, María, Diego Buffa, Hamurabi Noufouri, y Mario Ayala. Comps. Las poblaciones afrodescendientes de América Latina y el Caribe. Pasado, presente y perspectivas desde el siglo XXI. Córdoba: Universidad Nacional de Córdoba, 2012.

Beverley, John. Against Literature. Minneapolis: University Press of Minnesota, 1993. Borges, Jorge Luis. "El fin". Obras Completas 1. Buenos Aires: EMECÉ, 2002. 518-520. Borges, Jorge Luis y Margarita Guerrero. El Martín

Fierro. Buenos Aires: Columba, 1953.

Bourdieu, Pierre. Campo del poder y campo intelectual. Buenos Aires: Folios, 1983.

Bracco, Diego. Memorias de Ansina. Montevideo: Fin de Siglo, 1994.

Burgos, Elizabeth. Me llamo Rigoberta Menchú y así me nació la conciencia. México: Siglo XXI, 1985. 
Depestre, René. "Saludo y despedida a la negritud". África en América Latina.

Manuel Moreno Fraginals Ed. México: Siglo XXI, 1987. 337-362.

Dijk, Teun Van. Communicating racism. Ethnic prejudice in thought and talk. Newbery Park, CA: SAGE, 1987.

Dussel, Enrique. 1492. El encubrimiento del otro. Bogotá: Anthropos, 1992.

Echeverría, Esteban. "El matadero". Esteban Echeverría. Obras

escogidas. Caracas: Biblioteca Ayacucho, 1991.

Equipo Interdisciplinario de Rescate de la memoria de Ansina. Ansina me llaman y ansina yo soy. Montevideo: Rosebud, 1996.

Ezeiza, Gabino. Nuevas canciones inéditas. Buenos Aires: Biblioteca Gauchesca, 1897.

-. La Batalla de Maipo. Buenos Aires: Comisión Centenario, 1910.

-. Glorias Radicales. Rosario: Biblioteca Rosarina, 1916.

-. Recuerdos del payador. Buenos Aires: Andrés Pérez Cuberes, 1946.

García Canclini, Néstor. Culturas híbridas. México: Grijalbo, 1990.

Gilroy, Paul. The Black Atlantic. Cambridge, Massachusetts:

Harvard University Press, 1993.

Hammerly Dupuy-Hamerly Peverini. Artigas en la poesía de América. Buenos Aires: Noel, 1951.

Hernández, José. Martín Fierro. Buenos Aires: Centro Editor de América Latina, 1985.

Lewis, Marvin. Afro-Argentine Discourse: Another Dimension of the Black Diaspora. Columbia: University of Missouri Press, 1996.

Kaminsky, Amy. Argentina. Minneapolis: University of Minnesota Press, 2008.

Mármol, José. Manuela Rosas. Rasgos biográficos. Buenos Aires: Empresa administradora y reimpresora de obras americanas, 1917.

-. Amalia. Buenos Aires: Kapeluz, 1995.

Mignolo, Walter. The Darker Side of the Reinassance. Ann

Arbor: The University of Michigan Press, 1995.

Mills, Charles. The Racial Contract. Ithaca: Cornell University Press, 1999.

Mir,José María. Vox. Diccionario ilustrado Latino-Español, Español-Latino. Barcelona: Bibliograf, 1980.

Mitre, Bartolomé. Episodios de la Revolución. Buenos Aires: Editorial Universitaria de Buenos Aires, 1960.

Peluffo, Ana. Ed. Pensar el siglo XIX dese el siglo XXI. Raleigh: Acontracorriente, 2012.

Rosenblat, Ángel. El nombre de la Argentina. Buenos Aires:

Editorial Universitaria de Buenos Aires, 1964.

Sarmiento, Domingo Faustino. Facundo. Buenos Aires: Kapelusz, 1971.

Solomianski, Alejandro. Identidades secretas: La negritud argentina.

Buenos Aires: Beatriz Viterbo Editora, 2003. 
- "Gabino Ezeiza y su recuperación dentro del imaginario de la identidad nacional argentina". Cincinnati Romance Review 30 (2011): 52-68.

Sommer, Doris. Fundational Fictions. Los Angeles: University of California Press, 1991.

Stoll, David. Rigoberta Menchú and the Story of all Poor Guatemalans.

Boulder, Colorado: Westview Press: 1999.

Valldarez-Ruiz, Patricia. Ed. "Afro-Hispanic Subjetivities. Special Issue". Cincinnati Romance Review 30 (2011). 